\title{
Intestinal adaptation in short-bowel syndrome in infants and children: a collective review
}

Short-bowel syndrome is used to describe a condition of malabsorption and malnutrition resulting from the loss of absorptive surface area following massive smallbowel resection. The key to survival of patients with short bowel syndrome is the ability of the residual bowel to adapt. Postresection intestinal adaptation is influenced by several factors, including luminal nutrients, hormones and peptide growth factors. Enteral feeding is one of the major factors in stimulating intestinal adaptation after bowel resection. Between luminal factors promoting intestinal adaptation, pectin, short-chain triglycerides, free fatty acids and glutamine may be helpful. There is evidence in animal and clinical studies that some hormonal manipulation (growth hormone) improves adaptive small bowel growth after massive small bowel resection. Peptide growth factors are produced by epithelium of gastrointestinal tract and are classified into several discrete families on the basis of structural homologies and disparities. Many of these agents have been shown to enhance intestinal adaptation. Future clinical trials will be necessary to evaluate the roles of these growth factors in treatment of patients with short bowel syndrome. More work will be also required to resolve questions concerning how proadaptive agents may influence cellular and molecular mechanisms of nutrient absorption following bowel resection.

Short-bowel syndrome (SBS) is a condition characterized by a loss of intestinal length or competence,

\footnotetext{
I. Sukhotnik · N. Mor-Vaknin · C. M. Harmon

A. G. Coran

University of Michigan, Section of Pediatric Surgery,

Mott Children's Hospital, Ann Arbor, MI, USA

L. Siplovich · E. Shiloni

Rappaport Faculty of Medicine, Technion, Haifa, Carmel and Ha-Emek Medical Centers,

Haifa and Afula, Israel

I. Sukhotnik ( $\varangle)$,

Department Surgery B,

Carmel Medical Center, Haifa, Israel
}

resulting in a diminished ability to digest and absorb a regular diet [2]. Many authors define a loss of $50 \%$ or more of small-bowel length as SBS [8, 47]. SBS is a common problem in pediatric surgery and a significant cause of infant mortality and morbidity. Many clinical conditions in the neonate may necessitate intestinal resection; however, the most common indications are necrotizing enterocolitis, intestinal atresia, and volvulus $[2,8,47]$. Despite the availability of total parenteral nutrition (TPN) and advances in medical treatment, the morbidity of SBS remains strikingly high $[9,34]$. The key to survival after massive small-bowel resection is the ability of the residual bowel to adapt. In the early twentieth century it was first observed that massive small-bowel resection led to "compensatory hypertrophy" of the remaining gut [32]. In 1957 Pilling and Cresson [35] described the first successful extensive resection in two infants, who survived with only 26 and $28 \mathrm{~cm}$ remaining small bowel. Subsequently, many series of patients have documented survival in infants with even shorter small-bowel remnants [23, 38].

"Adaptation" is the term applied to the progressive recovery from intestinal failure following a loss of intestinal length [2]. Through the process of adaptation, the small bowel increases its absorptive surface area and its functional capacity to meet the body's metabolic and growth needs [50]. Intestinal adaptation begins within $48 \mathrm{~h}$ of resection, lasts for at least 18 months, and includes morphologic and functional changes of the residual bowel. Morphologic changes include lengthening of the villi, deepening of the crypts, increasing rates of enterocyte proliferation, increasing epithelial cell number per villus, and finally, an increase in the total number of enterocytes. Functional changes result in increasing nutrient uptake by isolated enterocytes. Several studies have shown that the functional integrity of the remaining intestine is of far more importance than the outward appearance of the bowel [9]. The enhanced intestinal absorption associated with the hyperplasia may permit compensation for the loss of proximal transport function and maintain normal growth. 


\section{Functional changes during adaptation}

Research on functional adaptation following massive small-bowel resection is organized around four questions: (1) the pattern of the adaptation: does transport of different nutrients increase or decrease following bowel resection? (2) the mechanistic basis for the adaptation: are the changes in nutrient transport due to changes in the number of existing enterocytes or to the production of new cells with different transport activity? (3) the time course and reversibility of adaptation; and (4) the factors influencing intestinal adaptation [24].

\section{Patterns of adaptation}

Several experiments have demonstrated that animals with resected intestine can often achieve virtually complete nutrient absorption by increasing their transport rates per $\mathrm{cm}$ intestine [24]. Mucosal hypertrophy and enhanced glucose absorption were demonstrated in the intestinal remnant in rats following extensive smallbowel resection; these changes developed after 2 weeks and were greater in the ileal remnant than in the jejunum [12]. Similar studies directed at intestinal protein metabolism in animals with SBS demonstrated an increase in activity of enterokinase and peptide hydrolase and increased uptake of amino acids per $\mathrm{cm}$ bowel length [18]. Absorption per $\mathrm{cm}$ of intestine is also increased for calcium [49] and other electrolytes. Rogers and Bochenek [39] demonstrated an increase in specific and total activity in the ileum of lipid re-esterifying enzymes after jejunectomy in rats.

\section{Mechanisms of functional adaptation}

A major impediment to the progress of research in the area of intestinal adaptation has been a lack of understanding the cellular and molecular mechanisms of increased intestinal nutrient transport following bowel resection. A very recent advance in this area has been the development and optimization of methods for determining different transporter genes and cellular transport systems. Hines et al. [20] have reported an increase in ileal sodium glucose cotransporter (SGLT1) mRNA expression after bowel resection. Additional evidence that SGLT1 cotransporter is involved in adaptation comes from the experiments of Sigalet and Martin [41].

The importance of epidermal growth factor (EGF) in intestinal adaptation is underscored by a number of recent studies in which increases in EGF receptor expression mRNA and protein have been shown in animals following bowel resection [14, 52]. Dodson et al. [11] analyzed cloned cDNA differentially expressed in adapting remnant ileum after $70 \%$ bowel resection and showed an increase in groups of genes involved in functional response (e.g., liver fatty acid-binding protein [L-FABP], apoprotein [apo IV], cellular retinol binding protein-II [CRBP II], and ileal lipid binding protein [ILBP]) and genes involved in cell-cycle regulation and cellular response to stress (e.g., glucoseregulated protein [grp78], protein phosphatase [PP1 $\delta]$, and pancreatitis-associated proteins [PAP I]). We have recently demonstrated an increase in long-chain fatty acid (LCFA) plasma-membrane transport protein FAT/CD36 in adapting remnant bowel in rats with SBS [43].

Time course and reversibility of adaptation

Determining the time course and reversibility of intestinal nutrient absorption and transport can be important in identifying the mechanisms of intestinal adaptation after bowel resection. Changes in intestinal transport rate that are completed in a few hours are unlikely to be mediated by gross structural changes, while a more delayed adaptive response may be related to changes in absorptive surface area and increases in total number of enterocytes [23]. The evidence for increased amino-acid transport following intestinal resection comes from experiments of Menge et al. [34]. We have recently examined a time course of food and fat intake, clearance, and absorbability in a rat model of SBS and found a decreased calculated fat and food absorption rate following massive small bowel resection [25].

Effect of pro-adaptive factors

on functional adaptation

Over the past decades, much research has focused on the identification of factors stimulating bowel regrowth. Little attention was given to evaluation of the effects of pro-adaptive agents on adaptation of intestinal nutrient transport. It has been shown that hepatocyte growth factor (HGF) may enhance carbohydrate absorption by up-regulating an intestinal epithelial glucose transporter gene [25]. The importance of interleukin 11 (IL-11) on absorptive function is underscored by a recent study in which IL-11 given subcutaneously enhanced substrate absorption after bowel resection [1]. Glucagon-like peptide-2 has been shown to enhance small-intestinal absorption in vivo in a rat model of SBS [25]. Iannoli et al. [21] showed that administration of growth hormone $(\mathrm{GH})$ significantly increases small-bowel brushborder membrane transport amino acids following small-bowel resection. Our laboratory has recently shown that LCFA may alter CD36 mRNA intestinal expression and fatty-acid transport by isolated enterocytes in a rat model of SBS [44]. Although several lines of evidence have demonstrated the importance of specific nutrients and certain trophic growth factors on intestinal growth and function, more work will be 
required to resolve questions concerning how proadaptive agents may influence cellular and molecular mechanisms of nutrient absorption following bowel resection.

\section{Anatomic changes during adaptation}

Another area about which there has been considerable debate is structural adaptation after massive smallbowel resection. A major focus of investigators in this area has been the elucidation of the molecular and cellular mechanisms underlying intestinal growth. Although traditional indices of adaptation (overall bowel and mucosal weight, mucosal DNA and protein, villus height, and crypt depth) are still relevant for intestinal growth studies, morphologic adaptation has recently been subjected to cellular and molecular analysis. The dynamic process of small-bowel turnover is a function of the rates of crypt-cell proliferation, migration along the small-bowel crypt-villus axis, and cell death via apoptosis [55]. The increase in villus height and crypt depth has been thought to be a result of cellular hyperplasia, leading to a marked increase in individual cell-surface area and overall absorption capability even though mucosal cellularity may be unaltered. There may also be a change in the enterocyte differentiation process as a part of adaptation.

Under normal circumstances, newly-formed immature enterocytes divide in the crypts of Lieberkühn and migrate to the villus tip, undergoing differentiation and maturation, and become capable of absorbing nutrients. Little is known about the effects of different pro-adaptive agents on the process of enterocyte differentiation. However, an increase in the proportion of fully-differentiated cells increases the total enterocyte transport pool and may significantly increase nutrient transport. Little data are available on the role of apoptosis, or programmed cell death, in preserving enterocyte mass following bowel resection. Apoptosis is a cascade of catabolic reactions leading to cell death by "suicide." This process can be initiated by different signaling pathways and is altered by many factors, including radiation, inflammation, and bowel resection [56]. Recent evidence demonstrates that apoptosis increases after bowel resection $[10,19]$. However, a reduction in the rate of apoptosis might indicate adaptive mechanisms to preserve enterocyte mass.

The identification of factors that promote growth and regeneration of the intestinal epithelium and reduce apoptosis will suggest new therapeutic strategies for augmenting intestinal adaptation. It has been reported that both enterocyte production and loss via apoptosis were decreased by reduced enteral intake in rats following bowel resection [10]. A major focus for investigators in this area will be to elucidate the effects of the other pro-adaptive factors on cellular proliferation and apoptosis following bowel resection.

\section{Accelerating adaptation}

The regulation of intestinal adaptation is maintained through the complex interaction of many different factors. These include nutrients and other luminal constituents, hormones, and peptide growth factors.

\section{Enteral feeding}

The initial management of patients with SBS involves TPN. However, it has been shown that enteral feeding is one of the major trophic factors in stimulating gut regrowth; therefore, once the patient demonstrates a stable clinical course, the postoperative ileus resolves, and the viability of the residual intestine is confirmed, enteral feeding should be attempted. The importance of enteral nutrition in the adaptation of the small intestine after resection has been confirmed by many studies [30, $35,53]$. However, the mechanism whereby food induces this adaptation is unknown. It is likely that enteral nutrition works through a number of mechanisms, including direct stimulatory effects on the epithelial cells themselves and stimulation of secretion of trophic hormones from the gastrointestinal (GI) tract [50]. Additionally, luminal nutrients increase pancreatobiliary secretion, gut neuronal activity, peristalsis, and splanchnic blood flow.

Not all nutrients have equally stimulating trophic effects. Research has recently been directed at those trophic factors that may in the future have therapeutic implications for patients with SBS. It has been suggested that pectin, short-chain triglycerides, LCFA, and glutamine have important roles as pro-adaptive agents in experimental animals with SBS [3]. The addition of pectin to enteral feeding in rats with SBS leads to a more rapid and higher adaptive response in the small and large bowel compared to control animals [27].

The amino acid glutamine is utilized as a major fuel by intestinal cells; however, the underlying molecular mechanisms of its anabolic effect are not clearly understood [54]. Animal studies and recent investigations in humans have demonstrated that glutamine alone [55] or combined with insulin-like growth factor (IGF) [56] or $\mathrm{GH}$ [4] can stimulate intestinal adaptation and reduce the degree of GI atrophy associated with TPN. LCFA appear to be more effective stimulators of intestinal adaptation than either medium-chain fats (MCF) or carbohydrates [50]. Consequently, a mixture of longand MCF is recommended for patients with SBS. MCF are recommended because they are tolerated more easily, and LCFA because they are important in stimulating intestinal adaptation. It has been reported that animals with SBS receiving an essential-fatty-acid deficient diet have significantly impaired intestinal mucosal hyperplasia [18]. We have recently shown that a high-fat diet both augments and accelerates intestinal adaptation in 
rats following bowel resection. The resected animals fed a high-fat diet showed signs of postresection mucosal adaptation on day 3 after operation, while the rats fed normal chow demonstrated signs of complete adaptation on day 14 [45].

\section{Pro-adaptive hormones}

There is evidence that some hormonal manipulation can improve intestinal adaptation in an animal model of SBS. The relationship between GH and events in the small intestine following bowel resection remains to be conclusively demonstrated. Earlier studies by Mainoya [32] demonstrated that GH can increase nutrient and electrolyte absorption in hypophysectomized animals. Later, Byrne et al. [5] reported that GH and dietary modification improved nutrient absorption in patients with SBS. It bears emphasis that similar studies performed in animal models of SBS showed no effect of GH on intestinal adaptation [51]. The effect of $\mathrm{GH}$ on adaptive processes is probably mediated through IGF-1, which is produced in the liver and may increase cryptcell production, villus height, and nutrient absorptive capacity [42].

\section{Peptide growth factors}

Several distinct peptide families have now been recognized to modulate growth in the GI tract [35]. Over the past 30 years, an increasing number of regulatory peptides produced by cellular constituents have been identified, and mechanisms whereby these factors modulate cell turnover in normal intestinal homeostasis have been studied. The peptide growth factors are classified into several discrete families on the basis of structural homologies and disparities [35]. They include the EGF transforming growth factor $\beta$ (TGF $\beta$ ), IGF, and fibroblast growth factor (FGF) families. In addition, a smaller number of peptide growth factors without structural similarities of the described families have also been identified and include HGF and platelet-derived growth factor (PDGF).

EGF was initially isolated by Cohen [7] from mouse submaxillary glands as the factor responsible for promoting premature eyelid opening in neonatal mice. Later, EGF was also identified within the GI tract and was shown to regulate cell proliferation and other functions through interaction with the mucosa at the luminal surface $[16,48]$. There is conflicting evidence concerning the effect of EGF on intestinal adaptation following bowel resection. Earlier studies in rat small intestine by Chaet et al. [6] demonstrated that EGF augments intestinal adaptation in the animal models of SBS. Further experiments have shown that EGF enhances functional enterocyte adaptation after small-bowel resection [13]. It bears emphasis that similar studies performed by Lukish et al. [31] in rats with SBS showed no effect of EGF on microscopic and ultrastructural features of the rat small-intestinal mucosa following massive small-bowel resection.

The second member of the EGF family, TGF $\alpha$, is a 50-amino-acid polypeptide that appears to act through the same receptor as EGF. TGF $\alpha$ has been demonstrated to directly promote cell proliferation and to exert a trophic effect on intact gastric, intestinal, and colonic mucosa [37]. Recently, TGF $\alpha$ has been shown to stimulate intestinal-cell proliferation via activation of EGF receptors in a rat model of SBS [15]. The role of the other EGF family members (amphiregulin, heparinbinding EGF, pox-virus growth factor, cripto, and heregulin) have not been examined for their role during intestinal adaptation, and future studies will be needed to evaluate these alternative EGF ligands during the adaptive response.

The IGF family includes three peptides: insulin, IGF-I, and IGF-II. The evidence that both IGF I and II are involved in modulation of growth and differentiation of normal small bowel comes from experiments by Laburthe et al. [28], who have shown that infusion of IGF I into rodent ileum resulted in a twofold increase in mucosal weight and other parameters of bowel growth. As alluded to above, IGF1 is produced in the liver in response to $\mathrm{GH}$, and may stimulate cell proliferation and increase villus height and nutrient absorptive capacity in an animal model of SBS [42]. Additional evidence that IGFI is involved in intestinal adaptation comes from experiments by Ziegler et al. [54], who showed that in rats with SBS ileal IGF-I mRNA expression rose nearly twofold during intestinal adaptation after bowel resection, which was augmented by IGF-I administration. Lukish et al. [31] have demonstrated that EGF and IGF1 increase substrate absorption after small-bowel resection in rats, and this increase in absorption persists after cessation of administration of these growth factors.

HGF is a distinctive growth-modulating peptide that has been identified in primary hepatocytes and is also expressed in stomach, small intestine, and colon [46]. After reviewing the evidence for the role of HGF as a pro-adapting agent after bowel resection, it should be mentioned that recent work by Kato et al. [26] has demonstrated a dramatic response in mucosal mass and enterocyte functional capacity following bowel resection in rats exposed to HGF. Other investigations have shown that HGF upregulates intestine epithelial glucose transporter gene expression, which is responsible for enhanced carbohydrate absorption in rats with SBS after HGF administration [24].

The effects of other peptide growth factors (FGF family, TGF $\beta$ family, and PDGF) on bowel growth have been examined in normal intestine, but have not been evaluated in an animal model of SBS. Future experiments will, therefore, be needed to examine the role of these factors and to elucidate the potential mechanisms by which they affect the adaptive response. 
Future directions

Despite enormous advances in our understanding of the cellular and molecular mechanisms of intestinal adaptation following massive small-bowel resection over the last decades, more questions have been raised than answered. Research on intestinal adaptation following massive small-bowel resection should address the following areas:

1. Detailed understanding of the mechanisms by which intestinal adaptation is stimulated is still lacking, and this may have important clinical implications. Further work is needed to define the full spectrum of factors that play a role in regulating growth in the GI tract and to elucidate the mechanisms through which they may affect bowel growth and nutrient absorption following bowel resection.

2. Understanding the pathophysiology of the augmented absorptive and digestive capacity of the remaining bowel is essential in the development of useful management strategies for patients with SBS. An important area of research will be to understand the basis of the role of different intracellular transport proteins on nutrient absorption. Further studies of enterocyte gene regulation and protein expression will be needed to determine the molecular and cellular mechanisms responsible for the enhancement of substrate absorption by several pro-adaptive factors beyond that that occurs with intestinal adaptation.

3. Further studies that define mechanisms of cell proliferation and apoptosis will be important to increase understanding of the regulation of intestinal adaptation. The identification of new factors that can promote intestinal cell proliferation and reduce apopto sis will suggest new therapeutic strategies in the treatment of patients with SBS.

4. Evidence thus far indicates that general nutritional status, specific nutrients, intestinal hormones, and peptide growth factors have important interactions that are necessary for stimulation of intestinal adaptation. Although the underlying mechanisms of these synergistic responses are unclear, intestinal adaptation after bowel resection may be facilitated by provision of both an appropriate nutrient background and exogenous gut-trophic hormones. Additional studies that determine basic mechanisms of nutrientgrowth factor interactions and the clinical efficacy of combinations of different pro-adaptive factors may be useful for defining new therapies in patients with SBS.

5. Finally, much is still to be learned about the ability of pro-adaptive factors to enhance intestinal adaptation in humans. Although several animal studies have identified a variety of factors promoting intestinal adaptation, only a few clinical trials have focused on the effect of these factors on intestinal growth in humans. The effects of $\mathrm{GH}$, glutamine, and diet modification have been examined in the treatment of patients with SBS [54]. Future experiments should be directed at evaluating the effects of other agents on intestinal adaptation in the clinical setting.

\section{References}

1. Alavi K, Prasad R, Lundgren K, Schwartz M (2000) Interleukin-11 enhances small intestine absorptive function and mucosal mass after intestinal adaptation. J Pediatr Surg 35: 371-374

2. Biller JA (1987) Short bowel syndrome. In: Grand RI, Sutphen JL, Dietz WH (eds) Pediatric nutrition. Theory and practice. Butterworths, Stoneham, pp 481-487

3. Booth IW, Lander AD (1998) Short bowel syndrome. Baillieres Clin Gastroenterol 12: 739-772

4. Byrne TA, Morrissey TB, Nattakom TV, et al (1995) Growth hormone, glutamine, and a modified diet enhance nutrient absorption in patients with severe short bowel syndrome. J Parent Ent Nutr 19: 296-302

5. Byrne TA, Persinger RL, Young LS, et al (1995) A new treatment for patients with short bowel syndrome. Ann Surg 222: $243-255$

6. Chaet MS, Arya G, Ziegler MM, Warner BW (1994) Epidermal growth factor enhances intestinal adaptation after massive small bowel resection. J Pediatr Surg 29: 1035-1038

7. Cohen S (1962) Isolation of a mouse submaxillary gland protein accelerating incisor eruption and eyelid opening in the new-born animal. J Biol Chem 237: 1155-1162

8. Coran AG (1993) Nutritional support. In: Ashcraft KW, Holder TM (eds) Nutrition in pediatric surgery. Saunders, Philadelphia, pp 19-41

9. Coran AG, Spivak D, Teitelbaum DH (1999) An analysis of the morbidity and mortality of short bowel syndrome in the pediatric age group. Eur J Pediatr Surg 9: 228-230

10. Cronk D, Ferguson DC, Thompson JS (2000) Malnutrition impairs postresection intestinal adaptation. J Parent Ent Nutr 24: $76-80$

11. Dodson BD, Wang JL, Swietlicki EA, Rubin DC, Levin MS (1996) Analysis of cloned cDNA differentially expressed in adapting remnant small intestine after partial resection. Am J Physiol 271: G347-G356

12. Dowling RH, Booth CC (1967) Structural and functional changes following small intestinal resection in the rat. Clin Sci 32: 139-149

13. Dunn JCY, Parungo CP, Fonkalsrud EW, McFadden DW, Ashley SW (1997) Epidermal growth factor selectively enhances functional enterocyte adaptation after massive small bowel resection. J Surg Res 67: 90-93

14. Falcone RA, Shin CE, Erwin CR, Warner BW (2000) Intestinal adaptation occurs independent of transforming growth factor-alpha. J Pediatr Surg 2: 365-370

15. Flint JM (1912) The effect of extensive resection of the small intestine. Bull Johns Hopkins Hosp 23: 127-144

16. Gallo-Payet N, Hugon JS (1985) Epidermal growth factor receptors in isolated adult mouse intestinal cells: studies in vivo and in organ culture. Endocrinology 116: 194-201

17. Garridio AB, Freeman HF, Chung YC, Kim YS (1978) Amino acid and peptide absorption after proximal small intestinal resection in the rat. Gut 20: 114-120

18. Hart MH, Grandjean CJ, Park JHY, Erdman SH, Vanderhoof JA (1988) Essential fatty acid deficiency and postresection mucosal adaptation in the rat. Gastroenterology 94: 682-687

19. Helmrath MA, Erwin CR, Shin CE, Warner BW (1998) Enterocyte apoptosis is increased following small bowel resection. J Gastrointest Surg 2: 44-49

20. Hines OJ, Bilchik AJ, Zinner MJ, Skotzko MJ, Moser AJ, McFadden DW, Ashley SW (1994) Adaptation of the $\mathrm{Na}+/$ glucose cotransporter following intestinal resection. J Surg Res 57: $22-27$ 
21. Iannoli P, Miller JH, Sax HC (1998) Epidermal growth factor and human growth hormone induce two sodium-dependent arginine transport systems after massive enterectomy. J Parent Ent Nutr 22: 326-330

22. Jackson RH (1925) Extensive resection of the small intestine in an infant. Surg Gynecol Obstet 40: 55-61

23. Karasov WH, Diamond JM (1987) Adaptation of intestinal nutrient transport. In: Johnson LR (ed) Physiology of the gastrointestinal tract, 2nd edn. Raven Press, New York pp 1489-1497

24. Kato Y, Yu D, Schwartz MZ (1998) Hepatocyte growth factor up-regulates SGLT1 and GLUT5 gene expression after massive small bowel resection. J Pediatr Surg 33: 13-15

25. Kato Y, Yu D, Schwartz MZ (1999) Glucagon-like peptide-2 enhances small intestinal absorptive function and mucosal mass in vivo. J Pediat Surg 34: 18-21

26. Kato Y, Yu D, Schwartz MZ (2001) Enhancement of intestinal adaptation by hepatocyte growth factor. J Pediat Surg: (in press)

27. Koruda MJ, Rolandelli RH, Settle RG, Saul SH, Rombeau JL (1986) Effect of a pectin-supplement elemental diet on intestinal adaptation to massive small bowel resection. J Parent Ent Nutr 10: 343-350

28. Laburthe M, Rouyer-Fessard C, Gammeltoft S (1988) Receptors for insulin-like growth factors I and II in rat gastrointestinal epithelium. Am J Physiol 254: G457-G462

29. Lemmey AB, Martin AA, Read LC, Tomas FM, Owens PC, Ballard FJ (1991) IGF-1 and the truncated analogues des-(13) IGF-1 enhance growth in rats after gut resection. Am J Physiol 260: E213-E219

30. Levine GM, Deren JJ, Yezdimir E (1976) Small-bowel resection: oral intake is the stimulus for hyperplasia. Dig Dis 21: 542-546

31. Lukish J, Yu D, Kato Y, Schwartz MZ (1996) The effect of certain growth factors on intestinal function and adaptation following massive small bowel resection. Gastroenterology 110 [Suppl]:A818

32. Mainoya JR (1982) Influence of ovine growth hormone on water and $\mathrm{NaCl}$ absorption by the rat proximal jejunum and distal ileum. Comp Biochem Physiol 71A: 477-479

33. Mayr JM, Schober PH, Weiensteiner U, Hllwarth ME (1999) Morbidity and mortality of the short-bowel syndrome. Eur J Pediatr Surg 9: 231-235

34. Menge H, Grafe M, Lorenz-Meyer H, Riecken EO (1975) The influence of food intake on the development of structural and functional adaptation following ileal resection in the rat. Gut 16: 468-472

35. Pilling GP, Cresson SL (1957) Massive resection of small intestine in the neonatal period. Report of two successful cases and review of the literature. Pediatrics 19: 940-948

36. Podolsky DK (1994) Peptide growth factors in the gastrointestinal tract, In: Johnson LR (eds) Physiology of the gastrointestinal tract, 3rd edn. Raven Press, New York, pp 129-167

37. Rickman PP, Irving I, Shmerling DH (1977) Long-term results following extensive small intestinal resection in the neonatal period. Prog Pediatr Surg 10: 65-75

38. Robinson MK, Ziegler TR, Wilmore DW (1999) Overview of intestinal adaptation and its stimulation. Eur J Pediatr Surg 9: 200-206
39. Rogers J, Bochenek W (1970) Localization of lipid re-esterifying enzymes of the rat small intestine. Biochim Biophys Acta 202: $426-433$

40. Sigalet DL, Martin GR (1998) Mechanisms underlying intestinal adaptation after massive intestinal resection in the rat. J Pediatr Surg 33: 889-892

41. Sigalet DL, Martin GR (2000) Hormonal therapy for short bowel syndrome. J Pediatr Surg 35: 360-364

42. Sukhotnik I, Gork SA, Chen M, Drongowski RA, Coran AG, Harmon CM (2000) Effect of a high fat diet on fatty acid translocase (FAT/CD36) expression and fatty acid transport in isolated enterocytes in a rat model of short bowel syndrome. Surg Forum 51: 525-527

43. Sukhotnik I, May N, Drongowski RA, Coran AG, Harmon CM (2000) Effect of dietary fat on fat absorption and concomitant plasma and tissue total lipid composition in a rat model of short bowel syndrome. J Pediatr Surg (in press)

44. Sukhotnik I, Gork SA, Chen M, Drongowski RA, Coran AG, Harmon CM (unpublished) Effect of dietary fat on very early intestinal adaptation in rats with short bowel syndrome

45. Tajima H, Matsumoto K, Nakamura T (1992) Regulation of cell growth and motility by hepatocyte growth factor and receptor expression in various cell species. Exp Cell Res 202: 423-431

46. Taylor SF, Sokol RJ (1995) Infants with short bowel syndrome. In: Hay WW (eds) Neonatal nutrition and metabolism. Mosby Year Book, St. Louis, pp 432-450

47. Thompson JF (1988) Specific receptors for epidermal growth factor in rat intestinal microvillus membranes. Am J Physiol 254: G429-G435

48. Urban E, Pena M (1974) In vivo calcium transport by rat small intestine after massive small bowel resection. Am J Physiol 226: G1304-G1308

49. Vanderhoof JA (1996) Short bowel syndrome. Neonat Gastroenterol 23: 377-386

50. Vanderhoof JA, Kollman KA, Griffin S, Adrian TE (1997) Growth hormone and glutamine do not stimulate intestinal adaptation following massive small bowel resection in the rat. J Pediatr Gastroenterol Nutr 25: 327-331

51. Warner BW, Vander Kolk W, Can G, Helmrath MA, Shin CE, Erwin CR (1997) Epidermal growth factor receptor expression following small bowel resection. J Surg Res 70 : $171-177$

52. Williamson RCN, Chir MB (1978) Intestinal adaptation: mechanisms of control. N Eng J Med 298: 1444-1450

53. Wyllie AH, Kerr JFR, Currie AR (1980) Cell death: the significance of apoptosis. Int Rev Cytol 68: 251-306

54. Ziegler TR, Smith RJ, Byrne TA, Wilmore DW (1993) Potential role of glutamine supplementation in nutrition support. Clin Nutr 12 [Suppl1]: S82-S90

55. Ziegler TR, Mantell MP, Chow JC, Rombeau JL, Smith RJ (1996) Gut adaptation and the insulin-like growth factor system: regulation by glutamine and IGF-1 administration. Am J Physiol 271: G866-G875

56. Ziegler TR, Estivariz CF, Jonas CR, Gu LH, Jones DP, Leader LM (1999) Interactions between nutrients and peptide growth factors in intestinal growth, repair, and function. J Parent Ent Nutr 23: S174-S183 